\title{
The role of radiation penetration in the energy budget of the snowpack at Summit, Greenland
}

\author{
P. Kuipers Munneke ${ }^{1}$, M. R. van den Broeke ${ }^{1}$, C. H. Reijmer ${ }^{1}$, M. M. Helsen ${ }^{1}$, W. Boot ${ }^{1}$, M. Schneebeli ${ }^{2}$, and \\ K. Steffen ${ }^{3}$ \\ ${ }^{1}$ Institute for Marine and Atmospheric Research, Utrecht University, Utrecht, The Netherlands \\ ${ }^{2}$ WSL Institute for Snow and Avalanche Research, Davos, Switzerland \\ ${ }^{3}$ Cooperative Institute for Research in Environmental Sciences, University of Colorado, USA
}

Received: 25 March 2009 - Published in The Cryosphere Discuss.: 8 April 2009

Revised: 19 June 2009 - Accepted: 26 June 2009 - Published: 3 July 2009

\begin{abstract}
Measurements of the summer surface energy balance at Summit, Greenland, are presented (8 June20 July 2007). These measurements serve as input to an energy balance model that searches for a surface temperature for which closure of all energy terms is achieved. A good agreement between observed and modelled surface temperatures was found, with an average difference of $0.45^{\circ} \mathrm{C}$ and an RMSE of $0.85^{\circ} \mathrm{C}$. It turns out that penetration of shortwave radiation into the snowpack plays a small but important role in correctly simulating snow temperatures. After 42 days, snow temperatures in the first meter are $3.6-4.0^{\circ} \mathrm{C}$ higher compared to a model simulation without radiation penetration. Sensitivity experiments show that these results cannot be reproduced by tuning the heat conduction process alone, by varying snow density or snow diffusivity. We compared the two-stream radiation penetration calculations with a sophisticated radiative transfer model and discuss the differences. The average diurnal cycle shows that net shortwave radiation is the largest energy source (diurnal average of $+61 \mathrm{~W} \mathrm{~m}^{-2}$ ), net longwave radiation the largest energy sink $\left(-42 \mathrm{~W} \mathrm{~m}^{-2}\right)$. On average, subsurface heat flux, sensible and latent heat fluxes are the remaining, small heat sinks $\left(-5,-5\right.$ and $-7 \mathrm{~W} \mathrm{~m}^{-2}$, respectively), although these are more important on a subdaily timescale.
\end{abstract}

\section{Introduction}

The energy balance at the surface of a snowpack is given by

$$
S W_{\mathrm{net}}+L W_{\mathrm{net}}+H_{\mathrm{sen}}+H_{\mathrm{lat}}+\tilde{G}_{s}=M,
$$

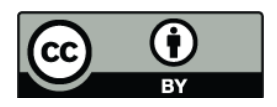

Correspondence to: P. Kuipers Munneke (p.kuipersmunneke@uu.nl) where the net shortwave radiation, $S W_{\text {net }}$, is the sum of global shortwave radiation, $S W_{\downarrow}$, and reflected radiation, $S W_{\uparrow}$; net longwave radiation, $L W_{\text {net }}$, is the sum of downwelling longwave radiation, $L W_{\downarrow}$, and upwelling longwave radiation, $L W_{\uparrow} ; H_{\text {sen }}$ is the turbulent sensible heat flux, $H_{\text {lat }}$ is the turbulent latent heat flux, $\tilde{G}_{S}$ is the subsurface heat flux at the surface, and $M$ is the amount of melt energy.

In the absence of meltwater percolation, the temperature distribution within the snowpack is governed mainly by heat conduction, which has a diffusive nature. Close to the surface, also non-diffusive processes take place, like subsurface penetration and subsequent absorption of shortwave radiation (Colbeck, 1989a), wind pumping (Colbeck, 1989b), and latent heat transfer by subsurface water vapour transport (Albert and Shultz, 2002). The latter two processes are known to play a role at high wind speeds. Earlier studies suggested that the subsurface heat production by penetration of shortwave radiation could be significant (Schlatter, 1972), leading to a "solid-state greenhouse" (Matson and Brown, 1989), in which shortwave radiation is absorbed below the surface while longwave radiation is emitted at the surface. Later, it was shown that these studies overestimated this effect as they did not take into account the large variation of the extinction coefficient of snow with wavelength (Brandt and Warren, 1993). Hence, the latter authors concluded that subsurface heating in Antarctica must be very small. The importance of treating subsurface radiation spectrally is underlined by experimental studies on subsurface radiation fluxes, e.g. by Meirold-Mautner and Lehning (2004) at Summit. Although it was shown that radiation penetration was overestimated previously, Liston and Winther (2005) suggested that no less than $20 \%$ of the snow-covered area of Antarctica experiences subsurface melt. Since most of this meltwater refreezes locally, the effect on the mass balance of Antarctica is supposed to be small. 
Although the effect was shown to be smaller than presumed before, it potentially affects the subsurface temperature distribution, since energy is transferred below the surface more efficiently than by conduction of heat from the surface layer alone. For ice, it was already demonstrated that radiation penetration plausibly explains observed vertical temperature distributions and vertical melt extent at several sites in the ablation zone of the Greenland ice sheet (Van den Broeke et al., 2008). For snow, the influence of radiation penetration on the formation of depth hoar (Alley et al., 1990) and crystal growth (Colbeck, 1989a) has been studied in detail, although the latter did not use a spectral model. Absorption of radiation below the surface leads to strong snow temperature gradients just below the surface. For a correct simulation of the effect of radiation penetration on snow temperature, it is therefore important to use a sufficiently high resolution of the subsurface model (Dadic et al., 2008).

In this study, we present detailed and high-quality measurements of the energy budget of the snowpack during two summer months at Summit, Greenland, and show that subsurface absorption of penetrated radiation plays an important role for the temperature distribution in the snowpack. In Sects. 2 and 3, the data and energy balance model are presented; Sect. 4 discusses the results, and the paper is concluded and summarized in Sect. 5 .

\section{Data and methods}

In this section, we present data acquired over a period of 42 days from 8 June to 20 July 2007, during the Summit Radiation Experiment (SURE '07), performed at the Greenland Environmental Observatory at Summit $\left(72^{\circ} 34^{\prime} \mathrm{N} 38^{\circ} 28^{\prime} \mathrm{W}\right.$, $3209 \mathrm{~m}$ a.s.l.), on top of the Greenland ice sheet.

\subsection{Automatic weather station}

A single-level automatic weather station (AWS) performed ventilated measurements of air temperature $T_{a}$, air pressure $p$, relative humidity $\mathrm{RH}$, and wind speed $u$ at $3.85 \mathrm{~m}$ above the surface. For the latter, a Young wind monitor was used. The specific humidity of air, $q$, is calculated from these data. Below the surface, subsurface snow temperatures $T_{s n, i}$ were measured at depths $z_{i}$ using thermistor strings $(0.20,0.30$, $0.50,0.75$ and $1.00 \mathrm{~m}$ ) and thermocouples (spaced $0.02 \mathrm{~m}$ up to $0.10 \mathrm{~m}$ ). AWS data were stored as 5 -min averages on a Campbell CR10X datalogger.

\subsection{Radiative fluxes}

The radiation components of the surface energy balance were measured with a separate installation equipped with highquality sensors for long- and shortwave radiation. $S W_{\text {net }}$ was measured with a pair of Kipp \& Zonen (K\&Z) CM21 pyranometers (the upward-looking one being ventilated); $L W_{\text {net }}$ was measured using K\&Z CG4 pyrgeometers (again, the upward-looking one being ventilated). The radiation data were stored as 1-min averages.

The upward-looking pyranometer regularly suffered from rime accretion during clear nights, which was removed manually every morning around 07:15 a.m. local time (09:15 UTC). $S W_{\downarrow}$ data suspected to be corrupted by rime were replaced by parameterized data by linearly interpolating the albedo during the period of the data gap and using $S W_{\uparrow}$.

We compared the K\&Z CG4 $L W_{\text {net }}$ measurements with data acquired by Eppley Precision Infrared Radiometers (PIR) at the nearby candidate-BSRN radiation station (Baseline Surface Radiation Network, Ohmura et al., 1998). It was found that the CG4 $L W_{\uparrow}$ measurements were systematically overestimated $\left(3.5 \mathrm{~W} \mathrm{~m}^{-2}\right.$ on average, peaking at $5-7 \mathrm{~W} \mathrm{~m}^{-2}$ during daytime). Contrary to the BSRN measurements, the CG4 sensor measuring $L W_{\uparrow}$ was not ventilated and its measurements were affected by window heating, i.e. heating of the sensor dome by reflected solar radiation. Since the thermal conduction between the dome and the thermopile measuring sensor housing temperature is near-perfect, the thermopile gets too warm and the calculated $L W$-fluxes too high. Window heating is less of a problem for the ventilated upward-facing CG4 $\left(1.9 \mathrm{~W} \mathrm{~m}^{-2}\right.$ difference with the Eppley PIR on average), but the BSRN Eppley PIR $L W_{\downarrow}$ measurements are preferred as they are shielded from direct solar radiation. Comparison of the $S W$-fluxes with those from the BSRN site showed that our measurements have less scatter (presumably due to regular removal of accreted rime). In the remainder of this manuscript, we will therefore use the $K \& Z$ CM21 $S W$-fluxes from our setup and the Eppley PIR $L W$ fluxes from the candidate-BSRN station. The latter are not affected by the formation of rime.

\subsection{Turbulent fluxes}

The sensible heat flux was measured directly with a Campbell CSAT3 sonic anemometer at a frequency of $20 \mathrm{~Hz}$, and 5 min averages were stored on a separate Campbell CR10X datalogger. The sonic anemometer was fitted with a Campbell Chromel Constantan 75 micron thermocouple for temperature measurements. $H_{\text {sen, obs }}$ can be deduced from the measurements of vertical wind velocity and potential temperature variations $w^{\prime}$ and $\theta^{\prime}$, using the flux-profile relation

$H_{\text {sen }, \mathrm{obs}}=\rho_{a} c_{p}\left(\overline{w^{\prime} \theta^{\prime}}\right)_{z \text { son }}$,

where $\rho_{a}$ is the density of air, $c_{p}$ the specific heat capacity of dry air, and $z_{\text {son }}$ the sonic anemometer measurement height $(3.50 \mathrm{~m})$. Rime that sometimes accreted on the sonic anemometer did not lead to data loss, and was removed by gently pulling the guy wires of the AWS. The only detectable effect of accreted rime on the sonic anemometer 
measurements was a slight decrease in observed thermocouple temperature relative to the air temperature in the morning, when sublimation of rime extracts heat from the thermocouple wire.

The latent heat flux was not measured directly, but rather computed using the bulk aerodynamic method as explained in Sect. 3.

\subsection{Snow sampling}

During SURE '07, we collected several snow samples that were used to obtain vertical profiles of effective snow grain radius $r_{e}$ and snow density $\rho_{s n}$ in the top few $\mathrm{cm}$ of the snowpack. At five days between 29 June and 17 July, we fixed samples in a dyed solution of diethyl phthalate. These samples were transported to a cold laboratory in Davos, Switzerland, a surface section was cut out, and they were digitally photographed. Unbiased stereological counting of sample slices was used to get detailed profiles of $r_{e}$ and snow density in the top 5 to $6 \mathrm{~cm}$ (Matzl and Schneebeli, 2006). Density and $r_{e}$-profiles of four of these samples are shown in Fig. 6

\section{The energy balance model}

For the calculation of the energy budget of the snowpack, the model by Van den Broeke et al. (2005) was used (see also Van As et al., 2005; Giesen et al., 2008). The model calculates the energy fluxes of a skin layer without heat capacity, it employs the bulk aerodynamic method for turbulent fluxes (see Sect. 3.1), and it calculates the subsurface temperature profile using the one-dimensional heat-transfer equation (Sect. 3.3). Using $S W_{\text {net }}, L W_{\downarrow}$ and the AWS measurements as input, the energy balance in Eq. (1) is solved iteratively in order to find a value for $T_{s}$ for which the energy budget is closed. As we will see later, this iterative procedure makes the model very robust, and less susceptible to errors in input data: since all fluxes are interrelated, and a change in $T_{S}$ has opposing effects on different fluxes, errors in the input are strongly damped. This was also demonstrated in an error analysis by Van As et al. (2005). The model has a time step of $1 \mathrm{~min}$.

\subsection{Turbulent fluxes}

In the energy balance model, the turbulent fluxes are calculated using

$H_{\mathrm{sen}}=\rho_{a} c_{p} u_{*} \theta_{*}$

$H_{\text {lat }}=\rho_{a} L_{v, s} u_{*} q_{*}$,

where $L_{v, s}$ is latent heat of vapourization or sublimation, depending on the surface temperature $T_{s}$. The surface friction velocity $u_{*}$, and the turbulent scaling parameters for temperature $\theta_{*}$ and specific humidity $q_{*}$, are computed using the bulk method - a method that exploits Monin-Obukhov similarity theory for wind, temperature and moisture profiles in the surface layer. The following conditions are assumed at the surface: at the roughness length for momentum $z_{0, u}$, wind velocity $u\left(z_{0, u}\right)=0$; at the roughness length for temperature $z_{0, T}$, air temperature $T_{a}\left(z_{0, T}\right)=T_{s}$; and at the roughness length for moisture $z_{0, q}$, the air is saturated: $q\left(z_{0, q}\right)=q_{\text {sat }}\left(z_{0, q}\right)$. With the Monin-Obukhov length $L$,

$L=\frac{u_{*}^{2}}{\kappa g / \theta\left[\theta_{*}+0.62 \theta q_{*}\right]}$,

$u_{*}, \theta_{*}$ and $q_{*}$ can be expressed using measurements of $u, T_{a}$ and $q$ at measurement levels $z_{u}, z_{T}$ and $z_{q}$ :

$u_{*}=\frac{\kappa u\left(z_{u}\right)}{\ln \left(\frac{z_{u}}{z_{0, u}}\right)-\Psi_{m}\left(\frac{z_{u}}{L}\right)+\Psi_{m}\left(\frac{z_{0, u}}{L}\right)}$

$\theta_{*}=\frac{\kappa\left(T_{a}\left(z_{T}\right)-T_{s}\right)}{\ln \left(\frac{z_{T}}{z_{0, T}}\right)-\Psi_{h}\left(\frac{z_{T}}{L}\right)+\Psi_{h}\left(\frac{z_{0, T}}{L}\right)}$

$q_{*}=\frac{\kappa\left(q\left(z_{q}\right)-q_{s a t}\left(z_{0, q}\right)\right)}{\ln \left(\frac{z_{q}}{z_{0, q}}\right)-\Psi_{h}\left(\frac{z_{q}}{L}\right)+\Psi_{h}\left(\frac{z_{0, q}}{L}\right)}$.

In the above equations, $\kappa=0.4$ is the Von Kármán constant; $\Psi_{m, h}$ are vertically-integrated stability correction functions taken from Holtslag and de Bruin (1988) for stable conditions and Dyer (1974) for unstable conditions (which occur regularly during daytime at Summit - Cullen and Steffen, 2001; Cullen et al., 2007). Roughness length for momentum, $z_{0, u}$, is taken as a constant at $3.8 \times 10^{-4} \mathrm{~m}$, derived from sonic anemometer measurements. Values for $z_{0, T}$ and $z_{0, q}$ are calculated following Andreas (1987). Since $u_{*}$ (and $\theta_{*}$ and $q_{*}$ ) requires the calculation of $L$, which is in turn dependent on $u_{*}$ (and $\theta_{*}$ and $q_{*}$ ), the turbulent fluxes are solved iteratively.

\subsection{Radiation penetration}

The model includes a module to calculate subsurface radiation penetration of shortwave radiation following the method presented by Brandt and Warren (1993). The model is identical to the one used in Van den Broeke et al. (2008). This module employs the two-stream approach from Schlatter (1972), giving analytical functions for attenuation of shortwave radiation per wavelength. The module calculates radiation in 118 wavelength bands covering the solar spectrum, and uses Mie scattering coefficients derived from Warren (1984), updated with values from Warren et al. (2006) for the UV and visible wavelength range. The two-stream analytical functions require a constant snow density $\rho_{s n, r p}$ and effective snow grain 


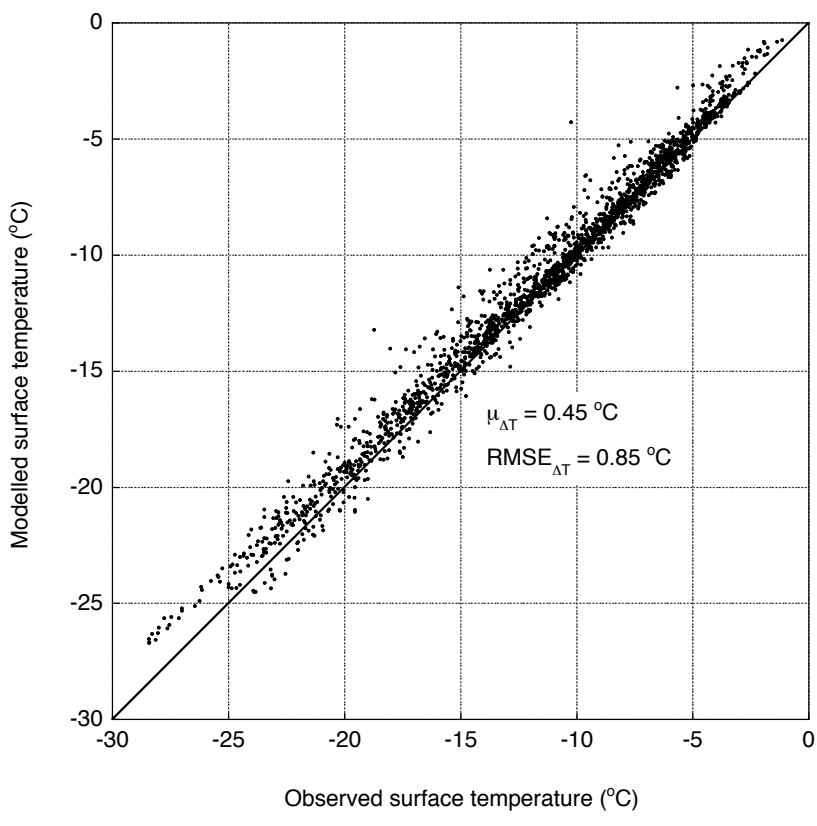

Fig. 1. $T_{S, \bmod }$ vs. $T_{S, \text { obs }}\left(\right.$ in ${ }^{\circ} \mathrm{C}$ ) for the optimal run. Radiation penetration is enabled, with $r_{e}=100 \mu \mathrm{m}$, and $\rho_{s n, r p}=280 \mathrm{~kg} \mathrm{~m}^{-3}$. Roughness length for momentum $z_{0, u}=3.8 \times 10^{-4} \mathrm{~m}$.

radius $r_{e}$. The grid spacing for the radiation penetration calculations is $0.001 \mathrm{~m}$. Results on this grid are interpolated onto the $0.01 \mathrm{~m}$ grid used for the subsurface calculations (see Sect. 3.3). Increasing the grid resolution any further did not affect the results.

Energy released by radiation penetration in the snowpack is added to the appropriate subsurface model layers, and the total amount of penetrated radiation $Q$ is subtracted from the surface skin layer. Equation (1), which is valid for the surface layer, formally becomes

$S W_{\text {net }}+L W_{\text {net }}+H_{\text {sen }}+H_{\text {lat }}+G_{s}-Q=M$.

For an infinitesimally thin surface layer, $S W_{\text {net }}=Q$ and these terms would cancel for the surface layer. Because of the discrete nature of the model numerics however, the surface layer energy budget retains the shape of Eq. (9).

The hypothesized effect of incorporating radiation penetration is that energy is released below the surface, enabling a more rapid warming of the snowpack.

\subsection{Subsurface flux}

To obtain the subsurface heat flux $G$, a subsurface module is included in the model, which calculates the one-dimensional heat-transfer equation on a $0.01 \mathrm{~m}$ grid up to a depth of $20 \mathrm{~m}$, beyond which $G$ is assumed to be zero. The model results are insensitive to grid size smaller than $0.01 \mathrm{~m}$. It was already pointed out by Dadic et al. (2008) that modelling of subsurface processes should be done at a sufficiently high resolution, as the temperature gradient attains large values.
The snow density profile, $\rho_{s n}(z)$ is prescribed using measurements from snow pits, and thus decoupled from the constant density required for the radiation penetration calculations. During the 42 days of the experiment, 7 snow pits were dug, in each of which we collected one pair of density profiles, spaced about $0.30 \mathrm{~m}$ apart to account for horizontal variations and to reduce the measurement error. The approximate vertical resolution is $0.02 \mathrm{~m}$ up to a depth of $1.0 \mathrm{~m}$. Density profiles were interpolated in time to account for temporal variations, and interpolated onto the $0.01 \mathrm{~m}$ subsurface grid. Below $1.0 \mathrm{~m}$, density is taken as a constant at $400 \mathrm{~kg} \mathrm{~m}^{-3}$.

Thermal conductivity of snow, $k_{s n}$, is prescribed as a function of $\rho_{s n}(z)$ (in $\mathrm{kg} \mathrm{m}^{-3}$ ), following Anderson (1976):

$k_{s n}=0.021+2.5\left(\frac{\rho_{s n}}{1000}\right)^{2}$.

The specific heat capacity of ice, $c_{p}$,ice, is a function of $T_{s n}(z)$. The vertical snow temperature profile was initialized using measurements typical for June at Summit (Hoch, 2005), scaled in the uppermost meter with our own measurements of $T_{s n}$.

The subsurface heat flux at the surface is denoted as $G_{S}$, and calculated using the model temperature gradient at the surface. To compare our energy budget calculations with previous studies (Cullen and Steffen, 2001; Hoch, 2005) that did not explicitly distinguish between subsurface heat fluxes by diffusion and subsurface radiation penetration, we will present their combined effects as $\tilde{G}_{S}$ using model snow temperatures (Hoch, 2005):

$\tilde{G}_{s}=-\sum_{j=1}^{n-1} \frac{\Delta T_{s n}\left(z_{j}\right) / \Delta t+\Delta T_{s n}\left(z_{j+1}\right) / \Delta t}{2}$
$\cdot c_{p, \text { ice }, j} \cdot \rho_{s n, j} \cdot\left(z_{j}-z_{j+1}\right)$.

The temperatures at the subsurface grid are used, and at $z=0$ the observed $T_{s, \text { obs }}$ is prescribed, making $n=2001$. By calculating $\tilde{G}_{S}$ in this way, the snowpack is regarded as a box containing a certain amount of heat, which is closed at the bottom (no heat exchange at the lower boundary) - the subsurface heat flux at the surface is thus assumed to equal the rate of change of the total heat storage in the snowpack, whether caused by heat diffusion or subsurface radiation absorption. In the terminology of the equations presented above:

$\tilde{G}_{s}=G_{s}-Q$,

assuming that other subsurface heat sources or sinks (e.g. wind pumping or water vapour transport) are negligible. In that case, $\tilde{G}_{s}$ is the same quantity as in Eq. (1).

\section{Results}

In this section, we present model results in the optimal setting, perform a sensitivity analysis, and demonstrate the role of radiation penetration in the energy budget of the snowpack. 


\subsection{Energy balance model results}

As described before, the AWS measurements, as well as the measurements of $S W_{\text {net }}$ and $L W_{\downarrow}$, drive the energy balance model. Its performance can be assessed by means of three criteria:

1. Calculated surface temperature $T_{s, \bmod }$ and observed surface temperature, $T_{s, \mathrm{obs}}$, derived from $L W_{\uparrow}$ measurements, should be in good agreement,

2. Calculated $H_{\text {sen }}$ and the directly measured $H_{\text {sen,obs }}$ from the sonic anemometer should be in good agreement,

3. The evolution of subsurface temperatures $T_{s n, i}$ in the model should agree with observed snow temperatures.

The optimal results of the energy balance model, determined by the best performance on the above-mentioned criteria, are shown in Fig. 1, which compares $T_{s, \bmod }$ and $T_{s \text {,obs }}$ (criterion 1). This calculation will be referred to as the "optimal run".

Figure 1 shows a small, systematic bias towards high $T_{s, \bmod }$, with $\mu_{\Delta T_{s}} \equiv \overline{T_{s, \bmod }-T_{s, \mathrm{obs}}}=0.45^{\circ} \mathrm{C}$ and a root mean square error $\left(\mathrm{RMSE}_{\Delta T_{s}}\right)$ of $0.85^{\circ} \mathrm{C}$. The model performs best for higher temperatures, whereas for lower temperatures, $T_{s, \text { mod }}$ tends to be too high. The discrepancy is not necessarily rooted in the model: $T_{s, \text { obs }}$ could be too low because of an offset in $L W$ measurements, which would be typically $1.9 \mathrm{~W} \mathrm{~m}^{-2}$ for $0.45^{\circ} \mathrm{C}$. This is well within the accuracy of the Eppley PIR pyrgeometers $\left(10 \mathrm{~W} \mathrm{~m}^{-2}\right)$. The difference $\mu_{\Delta T_{s}}$ turns out to be larger for clear-sky conditions, so either the model performs less well for meteorological conditions under a clear sky, or the measurements of $L W$ under clear sky are biased - or a combination of both.

In Fig. 2, we show a plot of modelled vs. measured sensible heat fluxes (criterion 2). The agreement is reasonable (correlation coefficient $r^{2}=0.66$ ). Negative values of $H_{\text {sen }}$ are somewhat underestimated by the model whereas positive values are overestimated. The surface layer over Summit is very shallow, possibly leading to some flux divergence between the surface and the sonic anemometer height (Hoch, 2005), conflicting with the assumption of a constantflux layer in the Monin-Obukhov theory. This might partly explain why the correlation between observations and the model results is not better, but this should be investigated further.

Lastly, we show the measured and modelled subsurface temperatures at $0.10,0.50$ and $0.75 \mathrm{~m}$ below the surface in Fig. 3a. As is clearly visible in this plot, modelled temperatures follow the measured ones quite well, although they do not match perfectly, and especially in the first weeks of the experiment period, there is some discrepancy in the amplitude of the daily cycle at depth. We will discuss these points in Sect. 4.3.

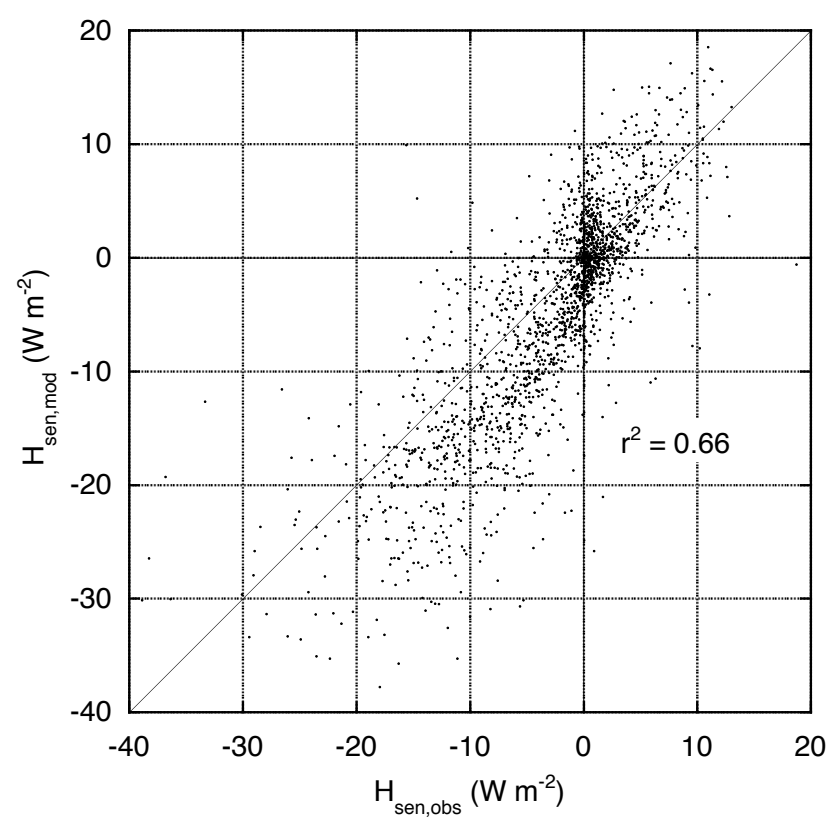

Fig. 2. $H_{\text {sen, mod }}$ vs. $H_{\text {sen, obs }}\left(\right.$ in $\mathrm{W} \mathrm{m}^{-2}$ ) for the optimal run.

\subsection{Sensitivity experiments}

In order to assess the sensitivity of the energy balance model to its settings and assumptions, we performed many sensitivity tests and compared the model outcome of each test with the optimal run. The results of 8 of these tests are summarized in Table 1. If $z_{0, u}$ is multiplied by $10, T_{s, \text { mod }}$ is hardly affected. Upon division of $z_{0, u}$ by $10, T_{s, \text { mod }}$ will deviate

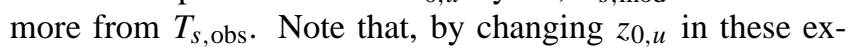
periments, the roughness lengths $z_{0, T}$ and $z_{0, q}$ are also affected through the relations by Andreas (1987). Limiting the stability correction functions slightly deteriorates the results, whereas omission of the stability correction functions altogether leads to a larger disagreement between $T_{s, \text { mod }}$ and $T_{s, \text { obs. }}$. The latter two tests show that applying an unlimited stability correction to the turbulent fluxes yields the best results. The robustness of the model regarding the turbulence calculations was also demonstrated by Van As et al. (2005).

Furthermore, we tested the sensitivity of model results to errors in the measured input. We varied $T_{2 m}$ by $\pm 0.1^{\circ} \mathrm{C}$ to show that the model results are moderately affected. A systematic temperature measurement error of $-0.7^{\circ} \mathrm{C}$ would be necessary to match $T_{s, \text { mod }}$ and $T_{s, \mathrm{obs}}$, which is deemed very unlikely, since the air temperature measurements agree very well with the independent thermocouple measurements from the sonic anemometer. Lastly, we increased snow densities $\rho_{s n}$ and $\rho_{s n, r p}$ by $50 \mathrm{~kg} \mathrm{~m}^{-3}$. We found that $T_{s, \text { mod }}$ rises by a moderate $0.04^{\circ} \mathrm{C}$. On the other hand, increasing snow density does have a small impact on modelled subsurface temperatures: the increase of $50 \mathrm{~kg} \mathrm{~m}^{-3}$ results in a $0.66^{\circ} \mathrm{C}$ higher temperature at $0.75 \mathrm{~m}$ after 42 days, and $+0.55^{\circ} \mathrm{C}$ at $0.10 \mathrm{~m}$. The explanation is that both the extinction of subsurface 

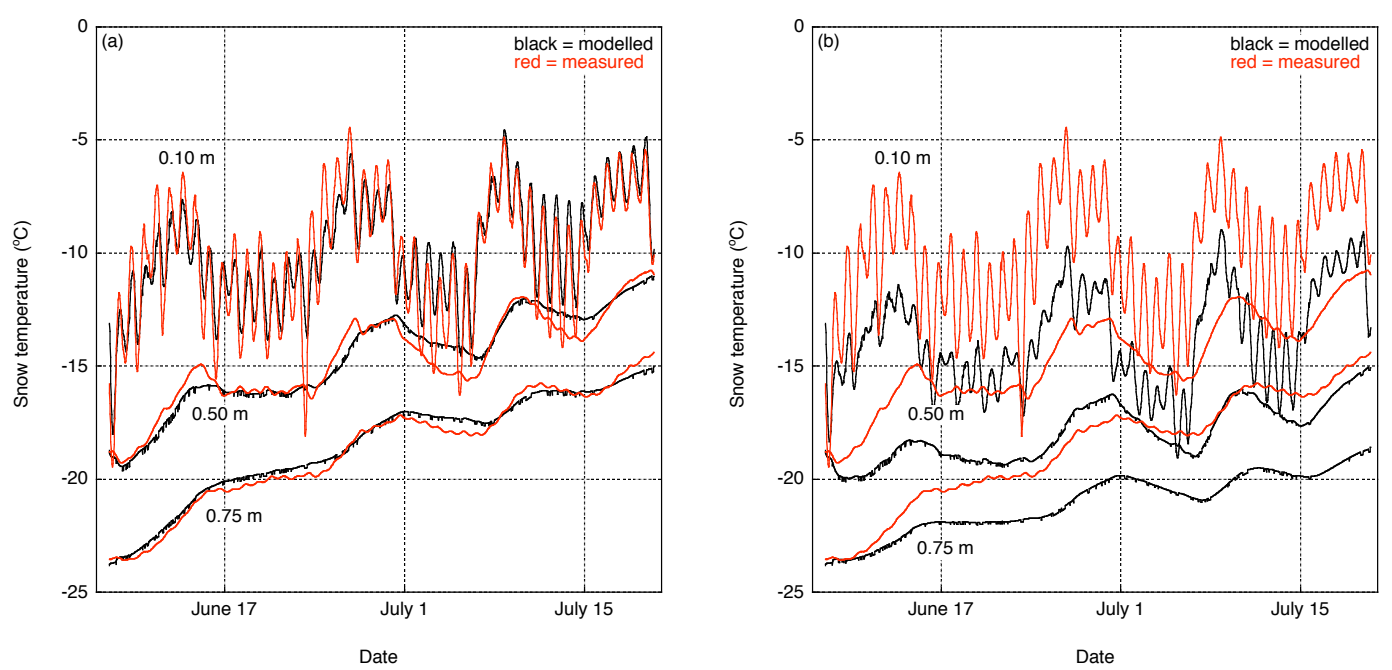

Fig. 3. Comparison between modelled (black) and observed (red) snow temperatures at $0.10 \mathrm{~m}, 0.50 \mathrm{~m}$, and $0.75 \mathrm{~m}$, for (a) the optimal run with radiation penetration, and (b) the run without radiation penetration, all other settings being equal.

Table 1. Overview of sensitivity studies performed with the energy balance model.

\begin{tabular}{lcc}
\hline Sensitivity test & $\mu_{\Delta T}\left({ }^{\circ} \mathrm{C}\right)$ & $\mathrm{RMSE}_{\Delta T}\left({ }^{\circ} \mathrm{C}\right)$ \\
\hline Optimal run & 0.45 & 0.85 \\
$z_{0, u} \times 10$ & 0.45 & 0.87 \\
$z_{0, u} / 10$ & 0.60 & 1.02 \\
Limited stability correction & 0.53 & 0.93 \\
No stability correction & 0.72 & 1.17 \\
$T_{a}+0.1^{\circ} \mathrm{C}$ & 0.52 & 0.89 \\
$T_{a}-0.1^{\circ} \mathrm{C}$ & 0.39 & 0.83 \\
Snow density $+50 \mathrm{~kg} \mathrm{~m}^{-3}$ & 0.49 & 0.89 \\
No radiation penetration & 0.47 & 1.03 \\
\hline
\end{tabular}

radiation and the heat conductivity increase, enabling better conduction of more absorbed radiation. However, without modelling radiation penetration, a higher density alone can never explain the observed snow temperatures. Different density-dependent formulations for thermal conductivity $k_{s n}$ (Eq. 10) have been tried, but the results changed insignificantly. In summary, tweaking the diffusive subsurface heat flux, either by varying $\rho_{s n}$ or $k_{s n}$ does not lead to a match between $T_{s, \text { mod }}$ and $T_{s, \text { obs }}$.

\subsection{Radiation penetration}

As a part of the sensitivity study in Sect. 4.2, the radiation penetration module was switched off. The resulting effect on the subsurface temperatures is shown in Fig. 3b. As can be clearly seen, the modelled snow temperatures remain systematically lower than the measured ones. Also, the amplitude of the signal at various time scales is underestimated.
Based on the following arguments, we rule out the possibility that the discrepancy between modelled and observed $T_{s n}$ can be explained by erroneous measurements due to radiative heating of the sensors: (1) Brandt and Warren (1993) performed a field experiment shading the snow surface, and from their findings it can be concluded that radiative heating of thermistors is by far too small at depths greater than 0.10 $\mathrm{m}$ to explain the discrepancy between measured and modelled snow temperatures; (2) the discrepancy persists during the night when the solar flux is small. Brandt and Warren (1993) showed in their field experiment that errors due to radiative heating of thermistors vanish a few minutes after they are shaded. We would therefore expect that night-time readings are unaffected. What we observe is quite different however: at nighttime, measured and modelled snow temperatures do not converge; (3) the discrepancy between modelled and measured temperatures does not only play a role close to the surface $(0.10 \mathrm{~m})$, but also at greater depth $(0.50$ and $0.75 \mathrm{~m}$ ). The thermistors are shielded with a white plastic protective cover, that is highly reflective especially for the wavelengths that do penetrate to these depths. Only for the thermocouple at $0.10 \mathrm{~m}$, the amplitude of the measured $T_{s n}$ is greater than that of the modelled $T_{s n}$ until the beginning of July. This could be indicative of a small amount of radiative heating of the thermistor; (4) other studies using exactly identical thermistor strings (Reijmer and Oerlemans, 2002; Van As et al., 2005) did not detect radiative heating of thermistors either. Rather, we propose that subsurface absorption of shortwave radiation deposits heat in snow below the surface, enabling a more rapid heating of the snowpack than by the subsurface heat flux $G$ alone.

The amount of shortwave radiation absorbed below the surface is plotted in time in Fig. 4. Most of this radiation is absorbed close to the surface, and rapidly decreases with 


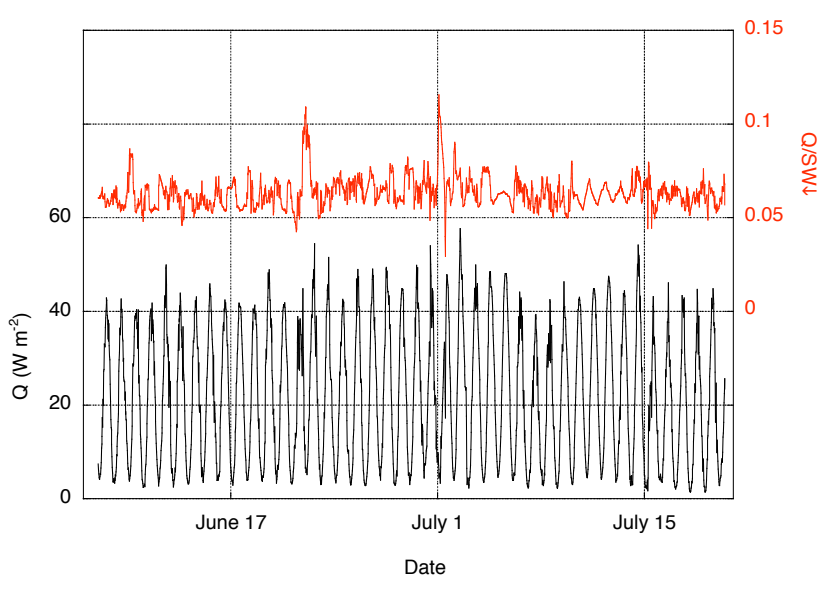

Fig. 4. Amount of radiation absorbed at least $0.5 \mathrm{~cm}$ below the surface $Q\left(\mathrm{~W} \mathrm{~m}^{-2}\right)$ in black, and its fraction of incoming solar radiation $S W_{\downarrow}$ in red.

depth. On average, $6.3 \%$ of the incoming solar radiation is absorbed at least $0.5 \mathrm{~cm}$ below the surface (in the second and subsequent subsurface model layers), which equals about $37 \%$ of $S W_{\text {net }}$.

In Fig. 3b, the peaks and troughs of modelled temperatures lag the observed ones by about $2 \mathrm{~h}$ and $20 \mathrm{~min}$ at $0.10 \mathrm{~m}$ depth. When radiation penetration is included (Fig. 3a), this lag reduces significantly, to $1 \mathrm{~h}$ and $12 \mathrm{~min}$. This supports the idea that absorption of shortwave radiation below the surface enables more and faster downward diffusion of energy into the snowpack.

From a physical point of view, subsurface absorption of radiation is emphatically different from the subsurface heat flux. The first is a source term, whereas the latter is a diffusive term. The implication of this fundamental difference is that adding a source term below the surface can successfully close the energy budget of the subsurface, whereas amending the diffusive process of heat conduction, by means of varying either $k_{s n}$ or $\rho_{s n}$ (Sect. 4.2), cannot. This is illustrated in Fig. 5, in which the subsurface snow temperature profile is plotted at the end of the 42-day experiment. Observed snow temperatures cannot be explained without radiation penetration, nor by increasing the snow density.

While the inclusion of subsurface absorption of radiation changes snow temperatures, it hardly affects the temperature at the surface. In Table 1, it is shown that the average difference between model and observations, $\mu_{\Delta T}$, changes insignificantly. This can be explained as follows. Almost all of the penetrated radiation is absorbed a few $\mathrm{cm}$ below the surface, leading to some local heating of the snow just below the surface (the "solid-state greenhouse effect" - Brandt and Warren, 1993). The temperature gradient close to the surface will decrease or even reverse, and as a result, $G$ increases close to the surface. For the energy balance of the surface layer (see Eq. 9), it means that the diminution of $S W_{\text {net }}$ by

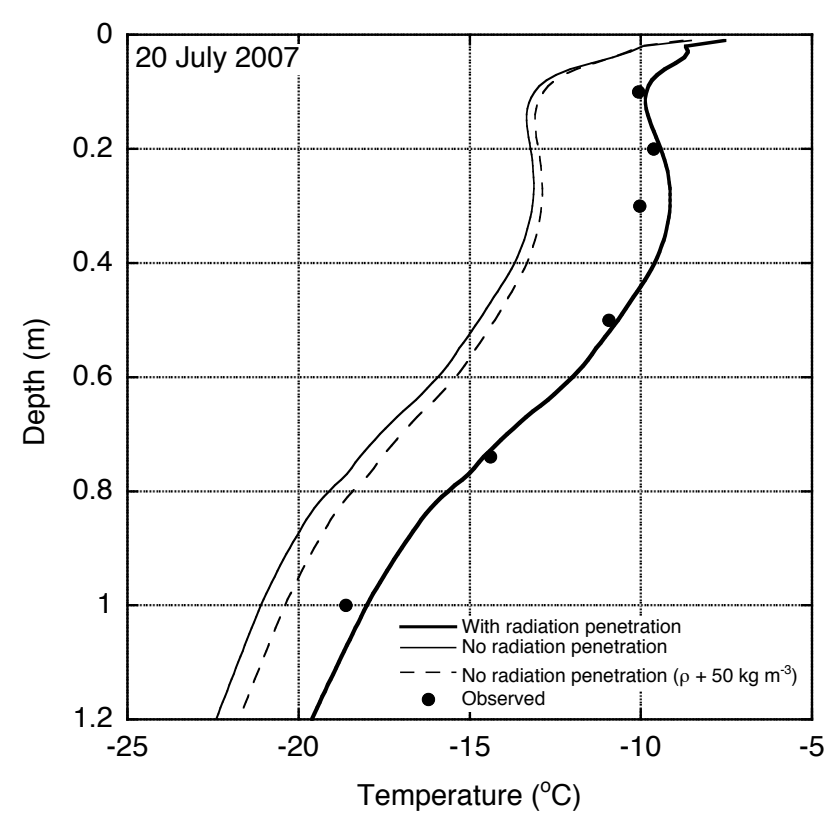

Fig. 5. Temperature profiles at the end of the 42-day experiment, measured (solid dots) and modelled, with radiation penetration (thick solid line), without radiation penetration (thin solid line) and without radiation penetration and higher snow density $\left(+50 \mathrm{~kg} \mathrm{~m}^{-3}\right)$ (thin dashed line).

the amount $Q$ is compensated for by an increase of $G_{s}$, leaving $T_{s, \text { mod }}$ almost unaltered.

\subsection{Radiative transfer modelling of radiation penetra- tion}

The radiation penetration model by Brandt and Warren (1993) requires a constant snow grain radius and snow density, as in fact, the equations in their model are analytical solutions from a set of coupled differential equations describing idealized two-stream radiative transfer (Schlatter, 1972). From stereographical analysis of snow samples (Sect. 2.4), we know that snow density and snow grain radius vary strongly in the top few $\mathrm{cm}$ of the snowpack. We therefore investigated the penetration of shortwave radiation with a doubling-adding broadband radiative transfer model (DAK - Doubling Adding KNMI). This model takes into account full multiple scattering within and between snow layers with different densities and snow grain radii, and provides a more accurate approximation to radiative transfer in a snowpack than the Brandt and Warren model. In the DAK model, ice crystals are prescribed using phase scattering functions (see Kuipers Munneke et al. (2008) for a complete description, and Wang et al. (2009) for clear-sky validation). The ice crystals have the same optical constants as the snow in the two-stream model.

We compared the two-stream model with the radiative transfer model DAK, applied to the snowpack at Summit. 


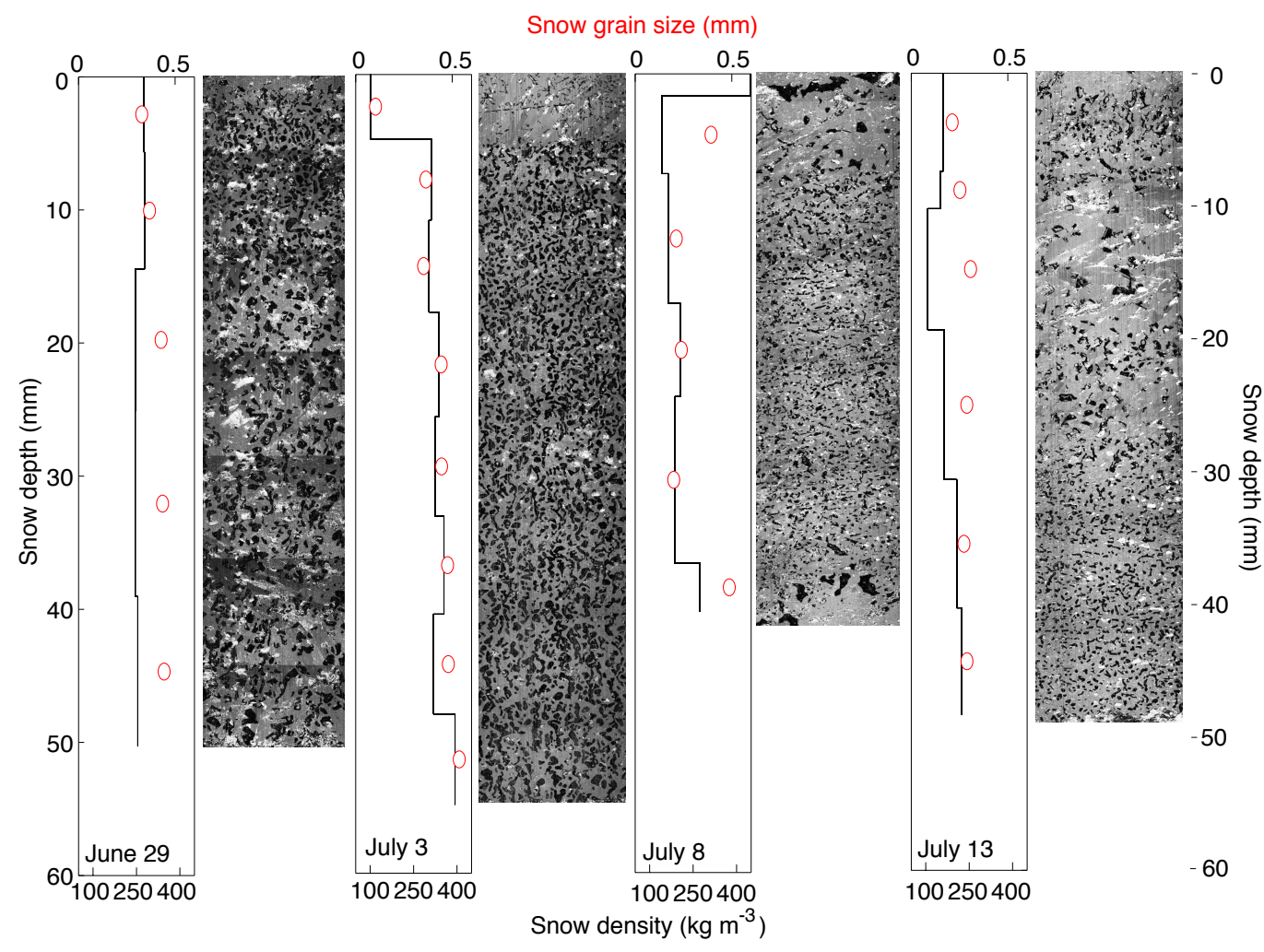

Fig. 6. Profiles of snow density (black lines, lower horizontal axis) and snow grain size (red circles, upper horizontal axis), from stereographical analysis of snow samples. The dates on which the snow samples were collected are displayed in each frame.

We selected four cases of clear-sky conditions close to which snow samples had been collected. For these cases, snow density and $r_{e}$-profiles were prescribed using the snow samples shown in Fig. 6. Radiosonde profiles were used to specify the atmospheric composition. Subsurface radiation absorption $d Q / d z$ profiles calculated by DAK are shown in Fig. 7a-d (red circles), together with results from the radiation penetration model for several values of $r_{e}$ and $\rho_{s, r p}=280 \mathrm{~kg} \mathrm{~m}^{-3}$ (black lines). All four plots show that radiation penetration in a snowpack with variable density and snow grain size is much more irregular than calculated with the idealized twostream model. For the cases in Fig. 7a-c, DAK results are close to the $100 \mu \mathrm{m}$-profiles, while in Fig. $7 \mathrm{~d}$, the $350 \mu \mathrm{m}$ profile better matches the DAK results. Which snow grain size in the Brandt and Warren (1993) model best describes the amount of absorbed radiation in the two-stream model depends very much on the density and snow grain size in the snow samples, and their vertical distributions.

The comparison between DAK and the two-stream model remains somewhat inconclusive. The vertical distribution of absorbed radiation is shown to be more complex than the two-stream model predicts, and results depend on snow density and snow grain size, as was shown by Brandt and Warren (1993). Measured snow grain sizes range from 100 to $500 \mu \mathrm{m}$, and densities from 100 to $450 \mathrm{~kg} \mathrm{~m}^{-3}$, but as Fig. 7 shows, the amount of absorbed radiation is sometimes better represented by choosing $r_{e}=100 \mu \mathrm{m}$ in the two-stream model, and at other times, $r_{e}=350 \mu \mathrm{m}$ fits better. For the simulation of snow temperatures by the energy balance model however, only $r_{e}=100 \mu \mathrm{m}$ gives correct results for the entire period. Whether this contradicts snow grain size measurements cannot be concluded unambiguously. Unfortunately, a coupling between the DAK model and the energy balance model is computationally prohibitive at present.

Both Colbeck (1989a) and Alley et al. (1990) have shown that radiation penetration facilitates the emergence of lowdensity snow layers (depth hoar) just below the surface, so that radiation penetration, subsurface heat flux, snow grain size and density become coupled. In our model, these couplings are all absent. Despite the above, the conclusion remains that the inclusion of subsurface absorption of solar radiation is crucial for modelling the energy budget of both the surface and the subsurface correctly.

\subsection{The diurnal cycle}

To conclude Sect. 4, the diurnal cycle of the components of the surface energy budget is presented, averaged over the entire measurement period. We compare our results with those reported by Hoch (2005) (H05) in June and July of 2001 and 2002. 

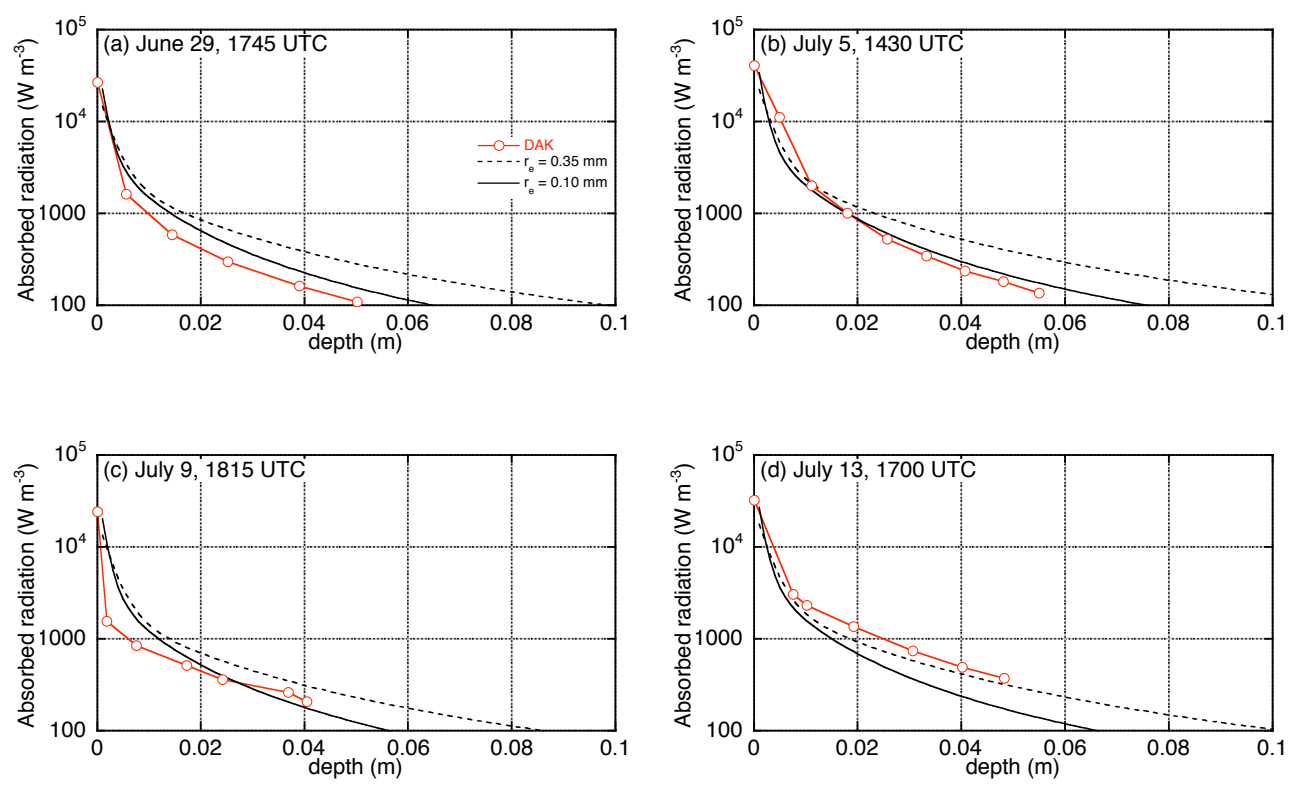

Fig. 7. Profiles of absorbed radiation in $\mathrm{W} \mathrm{m}^{-2}$ per $\mathrm{m}$. Red circles are calculations with the radiative transfer model DAK, whereas black lines are profiles from the two-stream model for snow grain radius $100 \mu \mathrm{m}$ (solid) and $350 \mu \mathrm{m}$ (dashed).

Figure 8 shows this diurnal cycle. By far the largest source of energy at the surface is $S W_{\text {net }}\left(+61 \mathrm{~W} \mathrm{~m}^{-2}\right.$ on average; $\mathrm{H} 05:+60 \mathrm{~W} \mathrm{~m}^{-2}$ ), whereas the largest sink is $L W_{\text {net }}\left(-42 \mathrm{~W} \mathrm{~m}^{-2} ; \mathrm{H} 05:-45 \mathrm{~W} \mathrm{~m}^{-2}\right)$. The average $L W_{\text {net }}$ minimum value of $-60 \mathrm{~W} \mathrm{~m}^{-2}$ occurs close to local noon (14:33 UTC), demonstrating that the temperatures of the surface snow and the air are instantly governed by solar radiation. Due to the inland location of Summit, advection of warmer air is negligible.

The turbulent fluxes are of comparable magnitude: $H_{\text {sen }}$ and $H_{\text {lat }}$ amount to -5 and $-7 \mathrm{~W} \mathrm{~m}^{-2}$, respectively (H05: $-1 \mathrm{~W} \mathrm{~m}^{-2}$ and $-9 \mathrm{~W} \mathrm{~m}^{-2}$ respectively), and act as small heat sinks. Between 21:00 and 06:00 UTC, $H_{\text {sen }}$ is a very small source of heat in a stably stratified near-surface boundary layer. Stronger mixing during daytime causes transport of heat from the surface to the air, as well as a small amount of sublimation (negative $H_{\text {lat }}$ ). On average, there is a very small amount of net deposition (fallout) or downward water vapour transport at nighttime (positive $H_{\text {lat }}$ ), although this is confined to a few nights during the measurement period. Combining the effects of diffusion from surface temperature, and radiation penetration, $\tilde{G}_{s}$ is $-5 \mathrm{~W} \mathrm{~m}^{-2}$ on average during the campaign ( $\mathrm{H} 05:-7 \mathrm{~W} \mathrm{~m}^{-2}$ ), reflected in a continuous heating of the snowpack (Fig. 3). The maximum cooling rate (positive $\tilde{G}_{s}$ ) of the snowpack is about $+14 \mathrm{~W} \mathrm{~m}^{-2}$ at night, and the maximum heating rate about $-25 \mathrm{~W} \mathrm{~m}^{-2}$ during daytime.

Cullen and Steffen (2001) report higher $S W_{\text {net }}$ $\left(+82 \mathrm{~W} \mathrm{~m}^{-2}\right)$ and lower $L W_{\text {net }}\left(-68 \mathrm{~W} \mathrm{~m}^{-2}\right)$ values, but those were obtained in a period with dominantly clear-sky conditions.

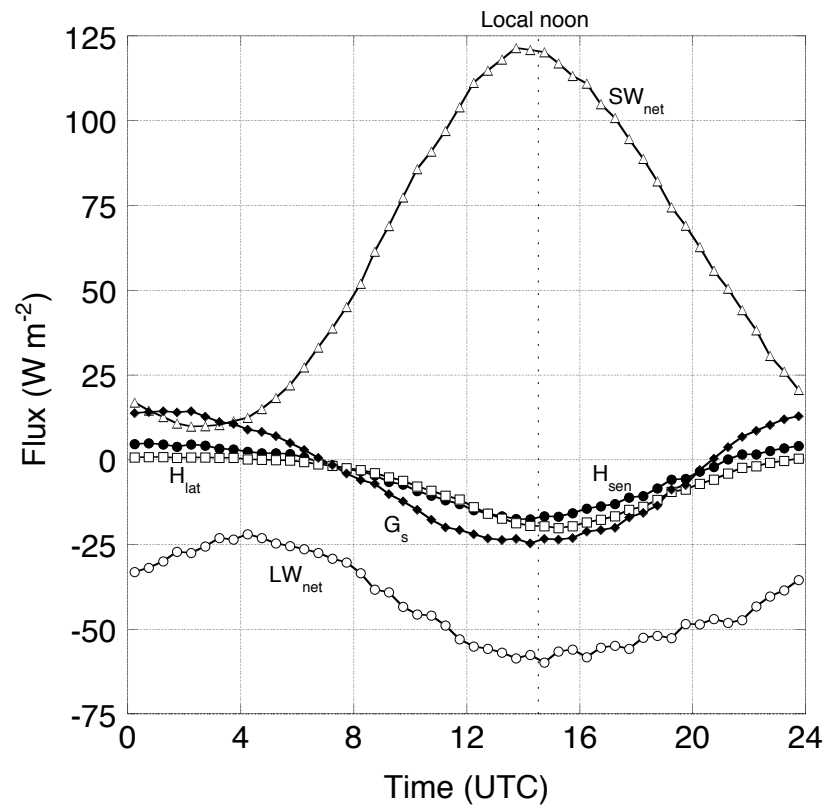

Fig. 8. Average diurnal cycle of the surface energy balance components, in $\mathrm{W} \mathrm{m}^{-2}$. Shown are net solar radiation (triangles), net longwave radiation (open circles), turbulent sensible (solid circles) and latent (open squares) heat fluxes, and subsurface heat flux (solid diamonds). The dashed vertical line represents the local noon at 14:33 UTC. 


\section{Discussion and conclusions}

In this study, we presented measurements and model results of the components of the energy balance of the snowpack at Summit, Greenland, during a 42-day period in June and July 2007. The energy balance model simulates observed snow surface temperatures well, although on average modelled and observed snow surface temperatures differ by $0.45^{\circ} \mathrm{C}$. The energy balance model was shown to be somewhat sensitive to the prescribed surface roughness length, and to small errors in input 2-m temperatures. Furthermore, the subsurface temperatures slightly depend on the prescribed snow density profile, but the effect is small in general. It was found that observed subsurface temperatures could not be reproduced without including a radiation penetration term in the energy balance model. Although observed snow grain radii in the top $5 \mathrm{~cm}$ range from 100 to $500 \mu \mathrm{m}$, subsurface temperatures could only be reconstructed using a radius of $100 \mu \mathrm{m}$. The use of a sophisticated radiative transfer model could not solve this possible discrepancy unambiguously, although for 3 out of 4 test cases, the $100 \mu \mathrm{m}$-profiles fit the radiative transfer model calculations best. Nevertheless, we argued that the inclusion of a radiation penetration term is required to close the energy budget of the snowpack satisfyingly.

A natural question that comes to mind is why subsurface absorption of shortwave radiation is apparently important at Summit, while it has not been reported to be necessary to close the energy budget at other locations, either those like Hardangerjøkulen, a small, temperate ice cap in Norway (Giesen et al., 2008), or in similar circumstances like the Antarctic Plateau (Van den Broeke et al., 2004; Van As et al., 2005). In the case of measurements on Hardangerjøkulen and melting glaciers in general, the energy fluxes from melt and internal refreezing, and the associated model uncertainties, largely exceed those of absorbed subsurface radiation or the subsurface heat flux, making it hard to assess what importance radiation penetration has in the heating of the snowpack. Before the start of the melt season at Hardangerjøkulen, the modelled snow temperatures are in fact lower than the measured ones (R. H. Giesen, personal communication, 2009), suggesting that radiation penetration has some effect on snow temperature, but this might also be attributed to some intermittent meltwater percolation and refreezing, not captured by the model. Considering that, on glaciers, snow grains can become large, snow can get wet or bare ice can appear at the surface, the magnitude of absorbed subsurface radiation will be larger than at Summit, but still smaller than melt energy fluxes. Regarding the Antarctic Plateau measurements, it could be that a combination of larger snow density (Van As et al., 2005) and smaller snow grains (Kuipers Munneke et al., 2008) makes the effect much less apparent, but this requires further study.
Acknowledgements. Fieldwork was conducted with logistical and field support from NSF/Veco Polar Resources. René van Overbeeke, Henk Snellen and Carina van der Veen (IMAU) are kindly thanked for fieldwork preparation. Stephen Steiner (SLF) is thanked for cutting and photographing the snow samples. We thank two anonymous reviewers and Mauri Pelto for their suggestions to improve this paper.

Edited by: S. Dery

\section{References}

Albert, M. R. and Shultz, E. F.: Snow and firn properties and airsnow transport processes at Summit, Greenland, Atmos. Environ., 36, 2789-2797, 2002.

Alley, R. B., Saltzman, E. S., Cuffey, K. M., and Fitzpatrick, J. J.: Summertime formation of depth hoar in Central Greenland, Geophys. Res. Lett., 17, 2393-2396, 1990.

Anderson, E. A.: A point energy and mass balance model of a snow cover, Tech. Rep. NWS19, NOAA, 1976.

Andreas, E. L.: A theory for the scalar roughness and the scalar transfer coefficients over snow and sea ice, Bound.-Lay. Meteorol., 38, 159-184, 1987.

Brandt, R. E. and Warren, S. G.: Solar-heating rates and temperature profiles in Antarctic snow and ice, J. Glaciol., 39, 99-110, 1993.

Colbeck, S. C.: Snow-crystal growth with varying surface temperatures and radiation penetration, J. Glaciol., 35, 23-29, 1989a.

Colbeck, S. C.: Air movement in snow due to windpumping, J. Glaciol., 35, 209-213, 1989b.

Cullen, N. J. and Steffen, K.: Unstable near-surface boundary conditions in summer on top of the Greenland ice sheet, Geophys. Res. Lett., 28, 4491-4493, 2001.

Cullen, N. J., Steffen, K., and Blanken, P. D.: Nonstationarity of turbulent heat fluxes at Summit, Greenland, Bound.-Lay. Meteorol., 122, 439-455, 2007.

Dadic, R., Schneebeli, M., Lehning, M., Hutterli, M. A., and Ohmura, A.: Impact of the microstructure of snow on its temperature: A model validation with measurements from Summit, Greenland, J. Geophys. Res. (D), 113, D14303, doi:10.1029/2007JD009562, 2008.

Dyer, A. J.: A review of flux-profile relationships, Bound.-Lay. Meteorol., 7, 363-372, 1974.

Giesen, R. H., van den Broeke, M. R., Oerlemans, J., and Andreassen, L. M.: Surface energy balance in the ablation zone of Midtdalsbreen, a glacier in southern Norway: interannual variability and the effect of clouds, J. Geophys. Res. (D), 113, D21111, doi:10.1029/2008JD010390, 2008.

Hoch, S. W.: Radiative flux divergence in the surface boundary layer. A study based on observations at Summit, Greenland, Ph.D. thesis, Swiss Federal Institute of Technology, Zürich, 2005.

Holtslag, A. A. M. and de Bruin, H. A. R.: Applied modelling of the night-time surface energy balance over land, J. Appl. Meteorol., 27, 689-704, 1988.

Kuipers Munneke, P., Reijmer, C. H., van den Broeke, M. R., Stammes, P., König-Langlo, G., and Knap, W. H.: Analysis of clear-sky Antarctic snow albedo using observations and radiative 
transfer modeling, J. Geophys. Res. (D), 113, D17118, doi: 10.1029/2007JD009653, 2008.

Liston, G. E. and Winther, J. G.: Antarctic surface and subsurface snow and ice melt fluxes, J. Climate, 18, 1469-1481, 2005.

Matson, D. L. and Brown, R. H.: Solid-state greenhouses and their implications for icy satellites, Icarus, 77, 67-81, 1989.

Matzl, M. and Schneebeli, M.: Measuring specific surface area of snow by near-infrared photography, J. Glaciol., 52, 558-564, 2006.

Meirold-Mautner, I. and Lehning, M.: Measurements and model calculations of the solar shortwave fluxes in snow on Summit, Greenland, Ann. Glaciol., 38, 279-284, 2004.

Ohmura, A., Dutton, E. G., Forgan, B., Fröhlich, C., Gilgen, H., Hegner, H., Heimo, A., König-Langlo, G., McArthur, B., Müller, G., Philipona, R., Pinker, R., Whitlock, C. H., Dehne, K., and Wild, M.: Baseline Surface Radiation Network (BSRN/WCRP): new precision radiometry for climate research, B. Am. Meteorol. Soc., 79, 2115-2136, 1998.

Reijmer, C. H. and Oerlemans, J.: Temporal and spatial variability of the surface energy balance in Dronning Maud Land, East Antarctica, J. Geophys. Res. (D), 107, 4759-4770, 2002.

Schlatter, T. W.: The local surface energy balance and subsurface temperature regime in Antarctica, J. Appl. Meteorol., 11, 10481062, 1972.

Van As, D., van den Broeke, M. R., Reijmer, C. H., and van de Wal, R. S. W.: The summer surface energy balance of the high Antarctic Plateau, Bound.-Lay. Meteorol., 115, 289-317, 2005.
Van den Broeke, M. R., van As, D., Reijmer, C. H., and van de Wal, R. S. W.: Assessing and improving the quality of unattended radiation observations in Antarctica, J. Atmos. Ocean. Tech., 21, 1417-1431, 2004.

Van den Broeke, M. R., Reijmer, C. H., van As, D., van de Wal, R. S. W., and Oerlemans, J.: Seasonal cycles of Antarctic surface energy balance from automatic weather stations, Ann. Glaciol., 41, 131-139, 2005.

van den Broeke, M., Smeets, P., Ettema, J., van der Veen, C., van de Wal, R., and Oerlemans, J.: Partitioning of melt energy and meltwater fluxes in the ablation zone of the west Greenland ice sheet, The Cryosphere, 2, 179-189, 2008, http://www.the-cryosphere-discuss.net/2/179/2008/.

Wang, P., Knap, W. H., Kuipers Munneke, P., and Stammes, P.: Clear-sky shortwave radiative closure for the Cabauw Baseline Surface Radiation Network site, the Netherlands, J. Geophys. Res. (D), in press, 2009.

Warren, S. G.: Optical constants of ice from the ultraviolet to the microwave, Appl. Optics, 23, 1206-1225, 1984.

Warren, S. G., Brandt, R. E., and Grenfell, T. C.: Visible and nearultraviolet absorption spectrum of ice from transmission of solar radiation into snow, Appl. Optics, 45, 5320-5334, 2006. 